\title{
Pengembangan Kualitas Perguruan Tinggi Islam Berdasarkan Keinginan dan Kebutuhan Stakeholder
}

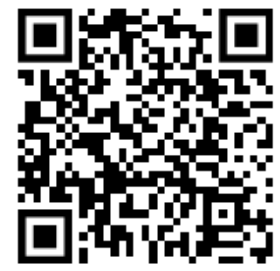

\author{
Septin Puji Astuti ${ }^{1}$, Datien Eriska Utami²
}

\begin{abstract}
Abstrak
Islamic University have to enhance their quality to make it more survive in this globalisation era. Consequently, it is important to identify the performance of the university. Apart from that, university stakeholder voices are important to be heard and it can be involved to increase the quality of higher education. For that reason, the main aim of this research is to identify Islamic university performance regarding to external stakeholder point of views. Hence, this research applied important-performance analysis to formulate the strategies for lifting the quality of university. For that purpose, 130 external stakeholders were gathered to be interviewed. Finally, it is found thatthe university has to pay more attention to improve the performance of computer facilities, their responsiveness to the development of the world and the fitness of curriculum to real world environment.
\end{abstract}

Kata Kunci: strategi, analisis impotance-performance, stakeholder needs and wants

\section{Pendahuluan}

Sekolah berbasis Islam meskipun telah diakui memiliki kesamaan status dengan sekolah umum (Umar, 2007), ternyata oleh masyarakat masih dinomor-duakan. Data dari Bagian Data dan Informasi STAIN Surakarta menunjukkan angka bahwa jumlah pendaftar pada gelombang kedua lebih besar dibandingkan pendaftar pada gelombang pertama. Gelombang kedua dibuka setelah pengumuman ujian masuk perguruan tinggi (umum) negeri. Hal ini sering terjadi terutama pada level yang lebih tinggi seperti Perguruan Tinggi. Salah satu alasan umum yang menjadi penyebabnya adalah jurusanjurusan yang ditawarkan masih kurang meyakinkan masyarakat bahwa lulusannya nantinya akan mendapatkan pekerjaan dengan cepat dan mudah. Karena alasan inilah beberapa Perguruan Tinggi Islam kemudian membuka jurusan-jurusan umum seperti Jurusan Ekonomi Islam, Sastra Inggris, dan Science and Technology, dengan harapan akan banyak pendaftar yang berminat sekolah di Perguruan Tinggi Islam.

Sekolah Tinggi Agama Islam Negeri (STAIN) Surakarta yang merupakan Perguruan Tinggi Islam memiliki beberapa potensi yang dapat membantu meningkatkan kualitasnya seperti sumber daya manusia, fasilitas yang cukup modern, dan didukung teknologi informasi yang cukup memadai. Namun, juga memiliki beberapa kelemahan yang antara lain adalah lulusan yang masih belum bisa bersaing dengan lulusan dari perguruan tinggi lain. Di samping itu sistem manajemen yang masih dirasa kurang mendukung peningkatan kualitas pengajar, staf, dan mahasiswa dirasa menghambat perkembangan STAIN Surakarta di masa depan. Oleh karena itu, maka perlu mereformulasikan strategi yang tepat sehingga mendukung keberlanjutan STAIN
Jurusan Ekonomika dan Bisnis Islam, STAIN

Surakarta, Jl. Pandawa, Kartasura, Sukoharjo, Jawa Tengah, Indonesia

* Email of Corresponding Author : septin.astuti@iain-surakarta.ac.id

Submitted : Agustus 2018

Accepted : Desember 2018

JAS-PT

JURNAL ANALISIS SISTEM PENDIDIKAN TINGGI ISSN 2580 - 5339 eISSN $2620-5718$ Volume 2 Nomor 2 DESEMBER 2018 Hal $71-82$ 
Surakarta dan semakin meningkatkan kualitas manajemen, pengajar, staf, dan mahasiswa.

Institusi pendidikan berhadapan dengan multilevel customer, sehingga harus fokus pada kebutuhan dan keinginan semua customer, baik internal maupun eksternal (Pitman, 1995). Dengan prinsip ini, walaupun STAIN Surakarta hanya menawarkan jurusan-jurusan yang memberikan banyak ilmu keagamaan dan hanya sedikit ilmu umum, tetap harus memenuhi keinginan semua customer dengan tanpa mengabaikan ciri khasnya yaitu Perguruan Tinggi yang berbasis pendidikan Islam. Untuk itu sangat diperlukan upaya-upaya strategis yang cukup efektif dan efisien supaya tujuan yang diinginkan dapt tercapai.

Pada kenyatannya, pengelola STAIN Surakarta telah merumuskan strategi-strategi untuk mengembangkan institusi. Namun, perumusan strategi tersebut seringkali tidak melibatkan suara customer yaitu mahasiswa atau stakeholder eksternal seperti pemerintah dan industri atau institusi pengguna lulusan STAIN Surakarta. Dengan kata lain, perumus strategi adalah stakeholder internal. Metode ini dirasa kurang tepat karena tidak mempedulikan apa keinginan dan kebutuhan stakeholder eksternal. Oleh karena itu, di dalam penelitian ini akan dilakukan uapya identifikasi kelemahankelemahan STAIN Surakarta sebagai dasar untuk merumuskan strategi berdasarkan keinginan dan kebutuhan salah satu stakeholder eksternal, yaitu mahasiswa.

\section{KAJIAN TEORI}

\section{Kualitas dan Stakeholder Perguruan Tinggi}

Definisi kualitas Perguruan Tinggi cukup beragam. Kanji dan Tambi (1999) menyatakan bahwa kualitas Perguruan Tinggi berkaitan dengan standar pengajaran dan pembelajaran, dan juga penelitian. Perguruan tinggi berkualitas juga dipahami sebagai lembaga pendidikan tinggi yang terkelola sedemikian rupa sehingga mampu menghasilkan jasa pendidikan tinggi sesuai dengan kebutuhan para pelanggan (Tampubolon, 2001). Kualitas di Perguruan Tinggi adalah stakeholder relative (Telford \& Masson, 2005).

Stakeholder atau customer perguruan tinggi dapat didefiniskan berbagai macam. Stakeholder adalah seseorang yang memiliki pengaruh di dalam proses atau dipengaruhi oleh Perguruan Tinggi seperti mahasiswa, pemilik institusi pendidikan, staf akademik dan non-akademik, pemerintah dan agen pemberi dana, penilai akreditasi, validator, auditor, asessor dan masyarakat secara luas (Telford \& Masson, 2005). Mereka bertanggungjawab atas dan berpartisipasi di dalam merancang dan pengiriman proses pendidikan di Perguruan Tinggi (Telford \& Masson, 2005). Customer perguruan tinggi berdasarkan lokasi dan posisinya terhadap perguruan tinggi dibagi menjadi dua kelompok yaitu customer internal dan eksternal (Telford \& Masson, 2005). Customer internal adalah pengelola perguruan tinggi, sedangkan customer eksternal terbagi atas tiga kelompok yaitu customer eksternal primer yaitu mahasiswa, customer eksternal sekunder yaitu orang tua, masyarakat, pemerintah, organisasi sponsor, dan lingkungan,

JAS-PT

ISSN $2580-5339$ elSSN $2620-5718$ Volume 2 Nomor 2

DESEMBER 2018 Hal 71- 82 dan customer eksternal tersier yaitu dunia kerja, lembaga pendidikan dan pelatihan, dan lingkungan (Telford \& Masson, 2005). Galloway (1998) mengatakan bahwa pengguna utama institusi pendidikan adalah siswa, namun selain itu juga ada customer lain yaitu industri, orangtua, pemerintah, dan masyarakat secara umum. 


\section{Pentingnya Mengukur Kualitas di Perguruan Tinggi}

Kualitas Perguruan Tinggi mencakup kualitas jasa dan produk. Keduanya sangat penting dievaluasi. AMA-Brussels menyatakan bahwa, dari hasil survey yang dilakukan oleh Management Associate Europe bekerja sama dengan American Association and Japanese management Association (Joseph et al., 2005), melaporkan bahwa delapan persen dari responden yang disurvei dari lebih 3300 pebisnis di Eropa, Amerika Utara, dan Jepang mengatakan bahwa meningkatkan kualitas pelayanan merupakan kunci untuk meraih kesuksesan kompetitif di pasar global.

\section{Diagram Important-Performance}

Diagram Important-Performance (IP) atau dikenal dengan important performance analysis (IPA) telah banyak diterapkan di berbagai industry (Wade \& Eagles, 2003). Tujuan dari penggunaan diagram IP adalah untuk memberi analisis strategis yang dapat membantu organisasi di dalam mengalokasikan sumber daya yang terbatas (Joseph et al., 2005). Sesuai dengan yang diusulkan oleh Martilla dan James (1977), di dalam analisis diagram ini diagram dikelompokkan ke dalam empat kuadran (Joseph et al., 2005). Empat kuadran tersebut ditampilkan dalam Gambar 1. Kuadran A (concentrate here) dimana stakeholder merasakan kinerja institusi sangat buruk tetapi menganggap sangat penting. Kuadran B (keep $u$ the good work) adalah dimana stakeholder memberi penilaian bagus pada kinerja institusi dan mengatakan bahwa hal tersebut dianggap penting di dalam institusi. Kuadran C (Iow priority) adalah dimana stakeholder menilai kinerja institusi buruk dan bukan hal yang terlalu penting. Kuadran D (possible overkill) adalah dimana stakeholder menilai kinerja baik namun bukan merupakan hal-hal yang terlalu penting.

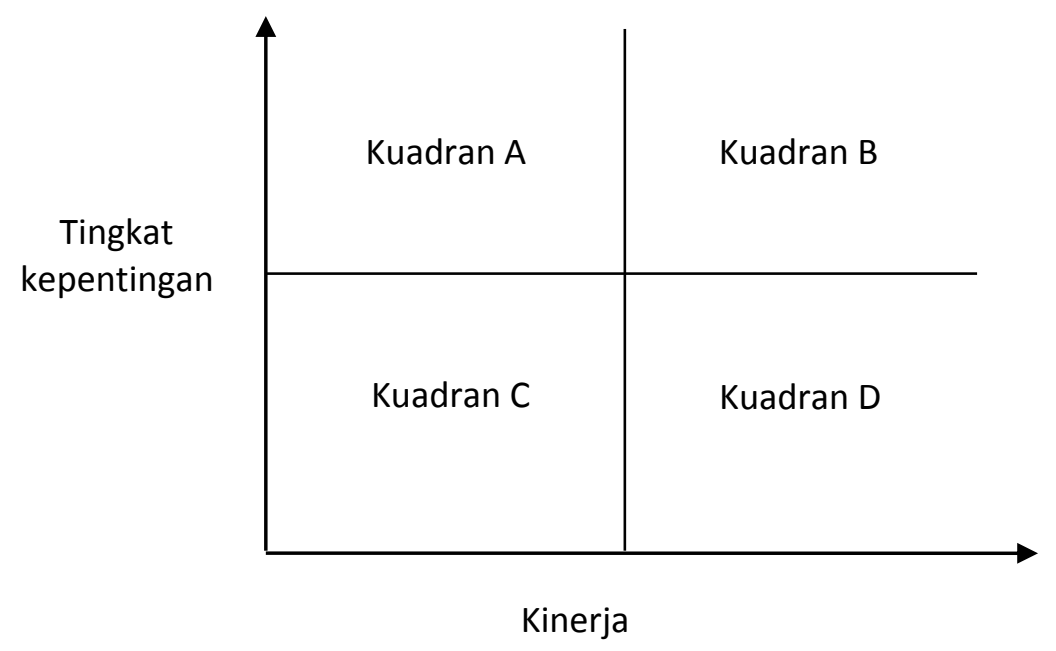

\section{Gambar 1: Diagram important-performance (IP)}

Diagram IP ini dapat digunakan untuk menentukan strategi peningkatan kualitas suatu organisasi. Apabila suatu organisasi berupaya untuk memberi kepuasan lebih kepada customemya tentu saja akan memfokuskan pada atribut-atribut yang oleh customer dinilai kinerjanya buruk, tetapi atribut tersebut adalah atribut yang penting (Kuadran A). Selain menggunakan diagram IP, untuk menilai kualitas dapat digunakan customer satisfaction index (CSI) yang diukur dengan rumus:

JAS-PT

JURNAL ANALISIS SISTEM PENDIDIKAN TINGG

ISSN $2580-5339$

eISSN $2620-5718$

Volume 2

Nomor 2

Desember 2018

Hal $71-82$

FORUM DOSEN INDONESIA 


$$
\text { CSI }=\frac{\text { Performance }}{\text { important to customer }} \times 100 \%
$$

CSI akan bernilai di bawah 1.0 apabila kinerjanya (performance) lebih rendah dari rendah tingat kepentingan (important to customer). Sebaliknya, CSI akan bernilai di atas 1 apabila kinerjanya lebih tinggi daripada tingkat kepentingan.

\section{Atribut Kualitas di Perguruan Tinggi}

Berbagai usulan mengenai atribut dan dimensi kualitas di Perguruan Tinggi telah diusulkan oleh banyak ahli. Owlia dan Aspinwall (1996) mengusulkan enam dimensi kualitas di Perguruan Tinggi yaitu tangible, competence, attitude, content, delivery, dan reliability. Dimensi tangible terkait dengan fasilitas-fasilitas fisik di Perguruan Tinggi, dimensi competence mengukur kompetensi pegawai dan dosen, dimensi content mengukur isi pembelajaran yang diberikan oleh dosen dan reliability mengukur kredibilitas institusi. Dimensi attitude mengukur perilaku dosen dalam hubungannya dengan mahasiswa dan bagaimana dosen mentransfer ilmu dan penilaiannya diukur di dalam dimensi delivery.

Dilihat dari berbagai literatur, ternyata tiap dimensi yang dibuat oleh tiap ahli berbedabeda. Oleh karenanya, perlu memperhatikan breakdown dari dimensi-dimensi tersebut atau dikenal dengan nama atribut kualitas yang lebih detail.

Mengenai atribut kualitas terutama di perguruan tinggi, para ahli juga memiliki perbedaan pendapat. Ada yang mengadopsi atribut kualitas SERVQUAL (Aigbedo \& Parameswaran, 2004; Galloway, 1998; Martin \& Adrian, 2004), MBNQA di pendidikan (Zohrabi \& Manteghi, 2011), dan HedPrev (Abdullah, 2005, 2006). Selain itu banyak peneliti menggunakan atribut lain seperti halnya Kwan dan $\mathrm{Ng}$ (1999) yang mengadobsi atribut Hampton.

\section{METODE PENELITIAN}

Dalam penelitian ini keputusan pengambilan strategi peningkatan kualitas di dasarkan pada analisis Important Performance Analysis (IPA). Untuk membangkitkan atributatribut kualitas yang diinginkan dan dibutuhkan oleh stakeholder dilakukan melalui dua cara yaitu penelitian lapangan yang melalui survei langsung ke stakeholder dan studi pustaka dari artikel jurnal yang membahas mengenai kualitas perguruan tinggi berdasarkan keinginan dan kebutuhan stakeholder. Apa-apa yang diinginkan dan dibutuhkan oleh stakeholder atau voice of customer (VOC) dilakukan melalui survei ke lapangan. VOC ini kemudian diintegrasikan dengan atribut-atribut kualitas berdasarkan SERVQUAL dan MBNQA di dalam pendidikan. Atribut-atribut VOC akan dapat diketahui setelah melakukan penelitian lapangan, sedangkan atribut-atribut kualitas SERVQUAL untuk pendidikan terdiri dari 22 item pertanyaan (Galloway, 1998; Martin \& Adrian, 2004). Selain atribut-atribut dari SERVQUAL, juga terdapat atribut-atribut kualitas yang dikembangkan Hampton (Kwan \& Ng, 1999).

JAS-PT

JURNAL ANALISIS SISTEM PENDIDIKAN TINGG ISSN $2580-5339$ elSSN $2620-5718$ Volume 2 Nomor 2

DESEMBER 2018 Hal 71- 82

FORUM DOSEN INDONESIA

\section{Data dan Sampling}

Dalam menyusun strategi pengembangan kualitas perguruan tinggi di dalam penelitian ini di dasarkan pada apa yang diinginkan dan butuhkan oleh stakeholder. Namun, di dalam penelitian ini difokuskan kepada stakeholder eksternal yaitu mahasiswa, orangtua mahasiswa, masyarakat, dan industri. Jumlah sampel yang diambil adalah 130 sampel yang diambil secara acak (simple random sample) dan merata untuk tiap kelompok stakeholder. 


\section{Teknik Pengukuran Kualitas}

Di dalam Important Performance Analysis (IPA) akan dinilai persepsi (kinerja) stakeholder terhadap STAIN Surakarta dan seberapa penting item-item pertanyaan tersebut menurut pandangan mereka. Persepsi dan tingkat kepentingan merupakan pertanyaan yang menanyakan sikap stakeholder atas pertanyaan. Oleh karenanya di dalam penelitian ini digunakan skala Likert.

Skala Likert yang banyak dikenal dan digunakan adalah skala Likert ganjil, yaitu skala 1 s/d 5 atau $1 \mathrm{~s} / \mathrm{d} 7$. Di dalam skala ini, terdapat sikap netral yang bagi manajemen kadangkala sulit sekali mengambil kebijakan ketika jawaban adalah netral atau tidak tahu. Karena alasan itulah, maka muncul ide skala Likert genap, yaitu skala $1 \mathrm{~s} / \mathrm{d} 4$ atau $1 \mathrm{~s} / \mathrm{d} 6$ (Arnold et al., 1967). Dengan angka genap akan menghindarkan penjawab memilih sikap netral atau tidak tahu, yang dapat membantu peneliti di dalam mengambil kesimpulan.

Di dalam penelitian ini digunakan skala Likert genap, karena untuk memudahkan di dalam pengambilan kesimpulan. Penilaian kinerja berdasarkan persepsi stakeholder adalah 1 (sangat-sangat buruk) sampai 6 (sangat-sangat baik). Adapun penilaian tingkat seberapa penting juga diukur dengan skala yang sama yaitu 6 , dimana 1 (sangat-sangat tidak penting), 2 (sangat tidak penting), 3 (tidak penting), 4 (penting), 5 (sangat penting), dan 6 (sangat-sangat penting).

\section{HASIL DAN PEMBAHASAN}

\section{Analisis deskriptif}

Dalam penelitian ini, jumlah kuesioner yang disebar ada 200 kuesioner, tetapi yang kembali berjumlah 136 dan kuesioner yang layak untuk dianalisis berjumlah 130 kuesioner. Adapun rincian indentitas responden ditunjukkan di dalam Tabel 2.

Terdapat lima kelompok responden yaitu mahasiswa, alumni, wali murid, masyarakat, dan dunia kerja. Responden dari dunia kerja berasal dari kalangan pendidik, lembaga keuangan syariah (LKS), swasta, dan pegawai Departemen Agama. Mahasiwa dan alumni merasakan langsung kinerja STAIN Surakarta. Sementara itu, wali murid, masyarakat, dan dunia kerja tidak merasakan langsung kinerja STAIN Surakarta, sehingga ada kemungkinan mereka memiliki pendapat yang berbeda dengan mahasiswa dan alumni. Oleh karenanya muncul dugaan ada perbedaan kinerja dan tingkat kepentian di tiap kategori responden. Rata-rata kinerja dan tingkat kepentingan tiap kategori responden ditunjukkan di dalam Tabel 3.

Untuk mengetahuinya signifikansi perbedaan raa-rata kinerja dan tingkat kepentingan antar kategori responden, maka dilakukan Analysis of Variance (ANOVA). Hipotesis awal $\left(\mathrm{H}_{0}\right)$ dalam uji ini adalah $\sigma_{1}=\sigma_{2}=\sigma_{3}=\sigma_{4}$ dan hipotesis alternatif $\left(\mathrm{H}_{1}\right)$ adalah min $\sigma_{i}=\sigma_{j}$, dimana $i, j=1,2,3,4$ dan $i \neq j$.

Dari ANOVA diperoleh nilai $p$-value untuk kinerja adalah sebesar 0,612 dan $p$-value untuk tingkat kepentingan adalah sebesar 0,189. Dari kedua nilai tersebut dan dengan menggunakan $\alpha=5 \%$, berarti gagal tolak hipotesis awal karena ternyata $p$-value tidak kurang dari 0,05 . Dari hasil ini berarti, bahwa dugaan bahwa pendapat tiap kategori responden adalah sama tidak dapat ditolak. Oleh karena itu untuk analisis berikutnya, semua jenis responden dijadikan satu untuk dianalisis bersama.

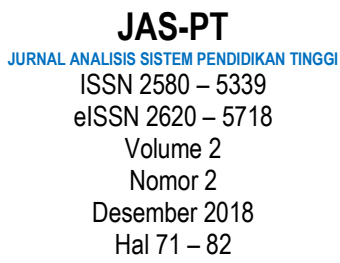

FORUM DOSEN INDONESIA 
Tabel 2: Identitas responden

\begin{tabular}{|c|c|c|c|}
\hline \multicolumn{2}{|l|}{ Identitas Responden } & \multicolumn{2}{|c|}{ Jumlah } \\
\hline \multicolumn{4}{|l|}{ Mahasiswa } \\
\hline Ushuludin & & 3 & \\
\hline Hukum Islam & & 4 & \\
\hline Tarbiyah & & 17 & \\
\hline Dakwah dan Komunikasi & & 11 & \\
\hline Ekonomika dan Bisnis Islam & & 19 & \\
\hline \multirow[t]{2}{*}{ Sastra Inggris } & & 5 & \\
\hline & & & 59 \\
\hline Alumni & & & 16 \\
\hline Orang tua mahasiswa & & & 16 \\
\hline Masyarakat & & & 21 \\
\hline \multicolumn{4}{|l|}{ Dunia Kerja } \\
\hline Pendidikan & & 5 & \\
\hline LKS & & 6 & \\
\hline Swasta & & 2 & \\
\hline \multirow[t]{3}{*}{ Pegawai Depag } & & 5 & \\
\hline & & & 18 \\
\hline & Jumlah & & 130 \\
\hline
\end{tabular}

Sumber: Data Primer Diolah

Tabel 3: Rata-rata kinerja dan tingkat kepentingan berdasar kategori responden

\begin{tabular}{llcccc}
\hline \multicolumn{1}{c}{ Variabel } & \multicolumn{1}{c}{ Responden } & N & Rata-rata & Min. & Max. \\
\hline Kinerja & Mahasiswa & 59 & 3.496 & 2.54 & 4.32 \\
& Orang tua mahasiswa & 16 & 3.443 & 2.77 & 4.25 \\
& Masyarakat \& Dunia Kerja & 39 & 3.370 & 1.91 & 4.45 \\
& Alumni & 16 & 3.374 & 2.04 & 4.54 \\
& Total & 130 & 3.437 & 1.91 & 4.54 \\
Tingkat & Mahasiswa & 59 & 4.944 & 3.50 & 6.00 \\
kepentingan & Orang tua mahasiswa & 16 & 4.752 & 3.57 & 5.36 \\
& Masyarakat \& Dunia Kerja & 39 & 4.798 & 3.57 & 5.96 \\
& Alumni & 16 & 5.091 & 3.95 & 6.00 \\
& Total & 130 & 4.895 & 3.50 & 6.00 \\
\hline
\end{tabular}

Sumber: Data Primer Diolah

JAS-PT

JURNAL ANALISIS SISTEM PENDIDIKAN TINGGI

ISSN $2580-5339$

elSSN $2620-5718$

Volume 2

Nomor 2

DESEMBER 2018

Hal 71- 82

FORUM DOSEN INDONESIA

\section{Analisis IP}

Penilaian kualitas dapat dilakukan oleh customer. Hal yang sama juga dapat diterapkan di dalam pendidikan, yang berarti bahwa kualitas pendidikan adalah apa yang dirasakan oleh stakeholder sebagai customer pendidikan. Apa yang dirasakan atau dipersepsikan oleh stakeholder di dalam analisis importance-performance (IP) diistilahkan dengan performance (kinerja). Rasio antara apa yang dirasakan dan tingkat kepentingan (importance) atas suatu atribut kualitas merupakan suatu indikasi 
kepuasan. Semakin kecil kinerja dan semakin besar tingkat kepentingan menunjukkan kepuasan yang sangat rendah yang berarti kualitas atas atribut tersebut adalah rendah.

Penilaian kualitas di dalam analisis IP juga dilakukan dengan diagram IP. Diagram IP ditunjukkan di dalam Gambar 2. Dalam diagram IP, kuadran A adalah yang harus menjadi perhatian utama karena pada diagram tersebut stakeholder menilai suatu atribut penting namun kinerjanya dinilai tidak baik. Dari penelitian ini, atribut-atribut yang masuk dalam kuadran $A$ adalah:

1. Kemodernan fasilitas untuk mahasiswa (atribut 1)

2. Ketersediaan tempat yang nyaman untuk belajar di kampus (atribut 2)

3. Kebersihan fasilitas yang digunakan mahasiswa (atribut 3)

4. Kualitas perpustakaan (atribut 6)

5. Ketersediaan fasilitas komputer (atribut 7)

6. Pegawai melayani tepat waktu (atribut 16)

7. Pembelajaran memenuhi kebutuhan mahasiswa dan dunia kerja (atribut 28)

8. Kesempatan kepada mahasiswa untuk mengembangkankemampuan dan mempersiapkan karir (atribut 29)

9. Kebermanfaatan modul di dalam mengembangkan karir mahasiswa (atribut 31)

10. Responsiveness atas perubahan jaman (atribut 56)

Sedangkan kuadran B adalah atribut yang dianggap penting dan kinerjanya dinilai baik. Atribut-atribut yang masuk di dalam kuadran B adalah:

1. Pegawai berpengetahuan (atribut 15)

2. Pegawai selalu sopan (atribut 19)

3. Ketersediaan sarana penghubung untuk merefleksikan ide-ide mahasiswa (atribut 27) Kualitas bahan ajar (atribut 30)

4. Kebermanfaatan modul di dalam memenuhi kebutuhan mahasiswa (atribut 32)

5. Wali studi di dalam membantu rencana studi mahasiswa (atribut 33)

6. Keinginan wali studi di dalam mengendalikan kemajuan mahasiswa (atribut 34)

7. Kemampuan wali studi di dalam membuat rencana pembelajaran (atribut 35)

8. Perhatian dosen terhadap mahasiswa (atribut 36)

9. Kesediaan dosen untuk berbicara dengan mahasiswa di luar kelas (atribut 37)

10. Penilaian terhadap mahasiswa yang rajin/ suka bekerja keras (atribut 40)

11. Ketepatan sistem penilaian (atribut 41)

12. Profesionalisme dosen di dalam mengajar (atribut 53)

13. Dukungan univ. bagi dosen/mahasiswa untuk melakukan penelitian (atribut 54)

JAS-PT

JURAL ANALISIS SISTEM PENDIDIKAN TINGG

ISSN $2580-5339$ elSSN $2620-5718$

Volume 2

Nomor 2

Desember 2018

Hal $71-82$

FORUM DOSEN INDONESIA 



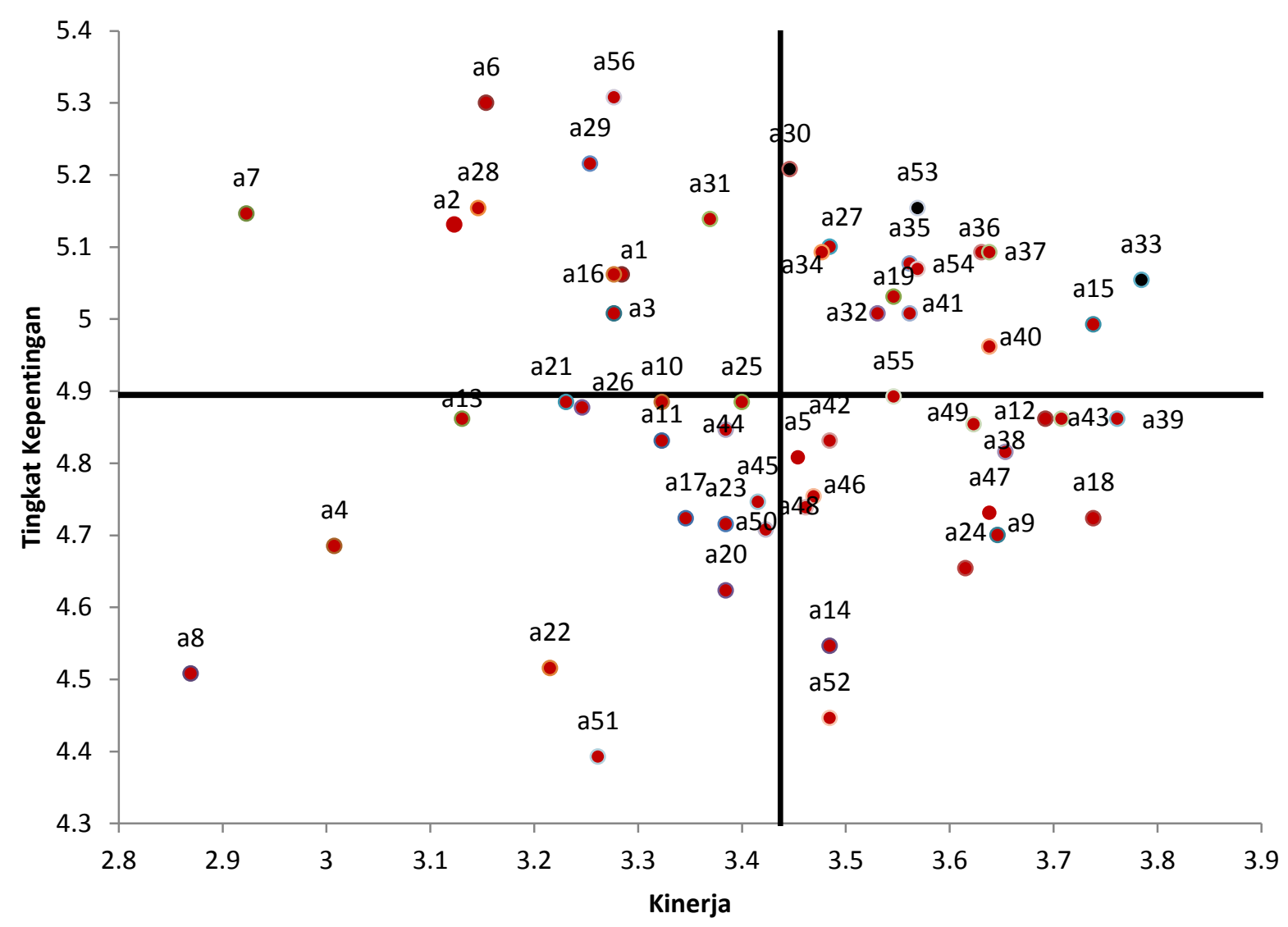

Gambar 1: Diagram IP 

Detail nilai CSI tiap atribut ditampilkan pada Tabel 4. Dari Tabel 4 nampak bahwa pada kuadran A, atribut ke-7 yaitu fasilitas komputer memiliki CSI sebesar 61.859, atribut ke56 yaitu responsiveness STAIN atas perubahan jaman memiliki CSI 63,82, dan atribut ke-28 yaitu pembelajaran memenuhi kebutuhan dunia kerja memiliki CSI sebesar 63, 91. Nilai CSI yang rendah ini berarti kepuasannya rendah, sehingga pada atribut-atribut tersebut harus dibenahi oleh STAIN Surakarta karena pada atribut tersebut tingkat kinerjanya rendah dan merupakan atrbut-atribut yang menurut pendapat stakeholder adalah atribut yang penting bagi Perguruan Tinggi Islam. Selain itu atribut 6 yaitu fasilitas perpustakaan (CSI $=64,270)$, atribut 2 yaitu tempat-tempat yang nyaman untuk belajar di kampus (CSI $=64,564)$, dan atribut 29 yaitu kesempatan bagi mahasiswa untuk mengembangkan kemampuan dan karir $(\mathrm{CSI}=64,718)$ juga merupakan atributatribut yang harus dibenahi oleh STAIN. Semua atribut yang termasuk di dalam kuadran A sebaiknya dibenahi terlebih dahhulu dibandingkan atribut lain, mengingat atribut-atribut di dalam kuadran tersebut adalah atribut yang dinilai kinerjanya buruk, tetapi juga merupakan atribut yang penting bagi Perguruan Tinggi.

Tabel 4: Daftar atribut beserta posisi di kuadran diagram IP

\begin{tabular}{cccccccc}
\hline \multicolumn{2}{c}{ Kuadran A } & \multicolumn{2}{c}{ Kuadran B } & \multicolumn{2}{c}{ Kuadran C } & \multicolumn{2}{c}{ Kuadran D } \\
\hline Atribut & CSI & Atribut & CSI & Atribut & CSI & Atribut & CSI \\
\hline 1 & 69.2436 & 15 & 77.7051 & 4 & 68.5000 & 5 & 74.6923 \\
2 & 64.5641 & 19 & 72.6667 & 8 & 67.3333 & 9 & 80.1795 \\
3 & 69.4615 & 27 & 70.4359 & 10 & 70.9744 & 12 & 80.1795 \\
6 & 64.2692 & 30 & 69.6667 & 11 & 79.2179 & 14 & 80.6154 \\
7 & 61.8590 & 32 & 73.2436 & 13 & 67.3974 & 18 & 81.8590 \\
16 & 67.6795 & 33 & 77.2436 & 17 & 74.0128 & 24 & 80.5385 \\
28 & 63.9103 & 34 & 70.8205 & 20 & 76.4231 & 38 & 78.7949 \\
29 & 64.7179 & 35 & 72.9615 & 21 & 68.5128 & 39 & 80.3846 \\
31 & 67.9103 & 36 & 73.4744 & 22 & 75.0897 & 42 & 74.8333 \\
56 & 63.8205 & 37 & 75.9872 & 23 & 74.2179 & 43 & 78.1026 \\
& & 40 & 76.2436 & 25 & 72.5385 & 46 & 75.3590 \\
& & 41 & 73.2308 & 26 & 69.9103 & 47 & 79.3077 \\
& 53 & 71.7821 & 44 & 72.3718 & 48 & 76.4744 \\
& 54 & 73.2692 & 45 & 75.2436 & 49 & 77.5256 \\
& & & & 50 & 75.0256 & 52 & 81.6154 \\
& & & & 51 & 79.7821 & 55 & 74.6410 \\
\hline
\end{tabular}

Atribut-atribut di dalam Kuadran B juga harus diperhatikan oleh STAIN Surakarta. Atribut yang termasuk di dalam kuadran ini berarti atribut yang kinerjanya dinilai baik dan merupakan atribut kualitas yang penting bagi Perguraun Tinggi. Atribut ke-30 yaitu kualitas bahan ajar, atribut ke-27 yaitu adanya sarana penghubung untuk merefleksikan ide-ide mahasiswa, dan atribut ke-34 yaitu keinginan wali studi untuk mengontrol kemajuan mahasiswa adalah atribut-atribut yang harus dijaga oleh STAIN Surakarta agar tetap baik. Karena atribut-atribut di dalam Kuadran B ini meskipun oleh stakeholder kinerjanya sudah dinilai baik tetapi juga merupakan atribut yang dirasa penting untuk diperhatikan kualitasnya.

Atribut-atribut pada kuadran B lebih harus diperhatikan oleh STAIN Surakarta daripada atribut-atribut di kuadran $C$ dan $D$. Hal ini karena atribut-atribut di kuadran $C$ dan $D$ bukan atribut-atribut yang kualitasnya dirasa cukup penting menurut pandangan

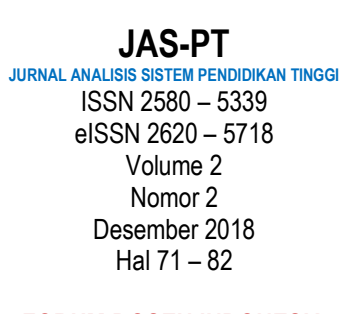

FORUM DOSEN INDONESIA 
stakeholder. Atribut di kuadran $\mathrm{C}$ boleh saja dibenahi, tetapi prioritasnya lebih tidak penting daripada atribut-atribut di kuadran A dan B. Apalagi untuk atribut-atribut di kuadran D. Karena kinerjanya sudah dinilai baik ditambah lagi bukan merupakan atribut yang kualitasnya begitu penting bagi stakeholder maka atribut-atribut di kuadran $D$ ini tidak harus diutamakan untuk dilakukan tindakan.

\section{KESIMPULAN}

Berdasarkan hasl penelitian ini, atribut-atribut yang temasuk di dalam kuadran $A$ adalah atribut-atribut yang harus dibenahi oleh STAIN Surakarta. Diantara atribut-aribut di dalam kuadran A, fasilitas komputer, daya tanggap STAIN atas perubahan jaman, dan pembelajaran memenuhi kebutuhan dunia kerja adalah atribut-atribut kualitas yang harus dibenahi terlebih dahulu untuk meningkatkan kepuasan stakeholder yang dampaknya nantinya akan menarik peminat/pendaftar di STAIN Surakarta dan akan meningkatkan kualitas input.

\section{ACKNOWLEDGEMENT}

Terima kasih kepada STAIN Surakarta (sekarang telah bertransformasi menjadi IAIN Surakarta) yang telah memberi kesempatan melakukan Program Penelitian STAIN Surakarta melalui dana DIPA STAIN Surakarta Tahun Anggaran 2009.

\section{DAFTAR PUSTAKA}

Abdullah, F. (2005). HEdPERF versus SERVPERF. Quality Assurance in Education, 13(4), 305-328. http://doi.org/10.1108/09684880510626584

Abdullah, F. (2006). Measuring service quality in higher education : HEdPERF versus SERVPERF, 24(1), 31-47. http://doi.org/10.1108/02634500610641543

Aigbedo, H., \& Parameswaran, R. (2004). Importance-performance analysis for improving quality of campus food service. International Journal of Quality \& Reliability Management, 21(8), 876-896. http://doi.org/10.1108/02656710410551755

Arnold, W. E., McCroskey, J. C., \& Prichard, S. V. O. (1967). The Likert-Type Scale. Today Speech, 15, 31-33.

Badri, M. a., \& Abdulla, M. H. (2004). Awards of excellence in institutions of higher education: an AHP approach. International Journal of Educational Management, 18(4), 224-242. http://doi.org/10.1108/09513540410538813

Galloway, L. (1998). Case studies Quality perceptions of internal and external customers : a case study in educational administration, 10(1), 20-26.

Joseph, M., Yakhou, M., \& Stone, G. (2005). An educational institution's quest for service quality: customers' perspective. Quality Assurance in Education, 13(1), 66-82. http://doi.org/10.1108/09684880510578669

JAS-PT

JURNAL ANALISIS SISTEM PENDIDIKAN TINGG

ISSN $2580-5339$

elSSN $2620-5718$

Volume 2

Nomor 2

DESEMBER 2018

Hal 71- 82

FORUM DOSEN INDONESIA
Kwan, P. Y. K., \& Ng, P. W. K. (1999). Quality indicators in higher education comparing Hong Kong and China's students. Managerial Auditing Journal, 14(1/2), 20-27. http://doi.org/10.1108/02686909910245964

Martin, A. O., \& Adrian, P. (2004). Importance-performance analysis: a useful tool for directing continuous quality improvement in higher education. Quality Assurance in Education, 12(1), 39-52. http://doi.org/10.1108/09684880410517423

Owlia, M. S., \& Aspinwall, E. M. (1996). A framework for the dimensions of quality in higher education. Quality Assurance in Education, 4(2), 12-20. 
http://doi.org/10.1108/09684889610116012

Pitman, G. (1995). QFD application in an educational setting : a pilot field study, 12(6), 63-72.

Tampubolon, D. P. (2001). Perguruan Tinggi Bermutu: Paradigma Baru Manajemen Pendidikan Tinggi Menghadapi Tantangan Abad ke-21. Jakarta: Gramedia Pustaka Utama.

Telford, R., \& Masson, R. (2005). The congruence of quality values in higher education, 13(2), 107-119. http://doi.org/10.1108/09684880510594364

Umar, Y. (2007). Depag upayakan para orang tua sekolahkan anaknya ke madrasah. Retrieved April 10, 2007, from http://www.depkominfo.go.id/index.php?action=view\&pid=news\&id=579

Wade, D. J., \& Eagles, P. F. J. (2003). The use of Importance-Performance Analysis and market segmentation for tourism management in parks and protected areas: An application to Tanzania's National Parks. Journal of Ecotourism, 2(April 2016), 196-212. http://doi.org/10.1080/14724040308668144

Zohrabi, A., \& Manteghi, N. (2011). WCETR 2011 A Proposed model for strategic planning in educational organizations. Procedia - Social and Behavioral Sciences, 28, 205-210. http://doi.org/10.1016/j.sbspro.2011.11.039 
JAS-PT

JURNAL ANALISIS SISTEM PENDIDIKAN TINGG

ISSN $2580-5339$

eISSN $2620-5718$

Volume 2

Nomor 2

DESEMBER 2018

Hal 71- 82

FORUM DOSEN INDONESIA 